\title{
ENTRAP and its potential interaction with European networks
}

H. Tietze-Jaensch ${ }^{1}{ }^{\text {** }}$, P. Van Iseghem ${ }^{2}$, L. Boucher ${ }^{3}$, A. Dodaro ${ }^{4}$, L. Fuks $^{5}$, J. P. Guisset ${ }^{6}$, S. Koivuranta ${ }^{7}$, C. Lierse $^{8}$, W. Neckel ${ }^{9}$, G. Piña ${ }^{10}$, S. Steyer ${ }^{11}$, L. Van Velzen ${ }^{12}$ and E. Vico del Cerro ${ }^{13}$

1 FZ Jülich Forschungszentrum Jülich GmbH, Institute of Energy and Climate Research, Nuclear Waste Management and Reactor Safety IEK-6, Leo Brand Str, 52425 Jülich, Germany

2 SCK $•$ CEN, Studiecentrum voor Kernenergie / Centre d'Etude de l'Energie Nucléaire, Boeretang 200, BE-2400 Mol, Belgium

3 CEA, French Alternative Energies and Atomic Energy Commission, 91191 Gif-sur-Yvette, Cedex, France

4 ENEA Casaccia, Italian National Agency for New Technologies, Energy and Sustainable Economic Development Nuclear Materials Characterization Laboratory, Via Anguillarese, 301 - 00123 S. Maria di Galeria, Rome, Italy

5 ICHTJ, CHTJ/INCT Institute of Nuclear Chemistry and Technology, 16 Dorodna Str., 03-195 Warsaw, Poland

6 JRC ISPRA, JRC Joint Research Centre ISPRA, Via Enrico Fermi, 2749, 21027 Ispra VA, Italy

7 VTT Espoo, VTT Technical Research Centre of Finland Ltd, P.O. Box 1000, FI-02044 VTT, Finland

8 TU München, ZTWB Radiochemie München RCM, Walther-Meißner-Str. 3, 85748 Garching, Germany

9 NES, Nuclear Engineering Seibersdorf GmbH, 2444 Seibersdorf, Austria

10 CIEMAT, URBMA/DFN/DE/CIEMAT, Av. Complutense, 40 Ed. 86T, 28040-Madrid, Spain

11 BfS, Bundesamt für Strahlenschutz (BfS), Willy-Brandt-Str. 5, 38201 Salzgitter, Germany)

12 NRG, Nuclear Research Group, Utrechtseweg 310 R42, 6812 AR Arnhem, The Netherlands

13 ENRESA, Empresa Nacional de Residuos Radiactivos, S.A. (ENRESA), C/ Emilio Vargas nº7, 28043 Madrid, Spain

[Received 10 October 2014; Accepted 22 April 2015; Associate Editor: Katherine Morris]

\section{ABSTRACT}

ENTRAP comprises a pan-European cooperation of leading scientific institutions and regulatory bodies in the field of nuclear-waste characterization and its quality assurance for the safe disposal of radioactive waste. Here, the scope of this cooperation is presented and explained and links or interfaces for a potential collaboration with partners fulfilling tasks of IDG-TP are pursued.

KEYWORDs: nuclear-waste characterization, destructive and non-destructive testing of radioactive waste forms, quality assurance of nuclear waste, safe disposal of radioactive waste.

\section{Introduction}

IN the early 1980 s, quality assurance (QA) policies were introduced in the field of nuclear-waste management. The European Commission (EC) through its 'Plan of Action' recognized the importance of a sound QA approach in the field

* Email: h.tietze@ffz-juelich.de

DOI: $10.1180 /$ minmag.2015.079.6.26 of nuclear-waste management, and in 1982 a working group was created to review the status of implementation of production standards and QA of radioactive waste in Europe. A global QA program requires a thorough inventory characterization and as a final step of quality control, the verification by quality inspectors operating independently of the waste conditioner of the predictable product properties of the radioactive waste package relevant to final disposal. To be successful, this QA-based approach requires application by responsible
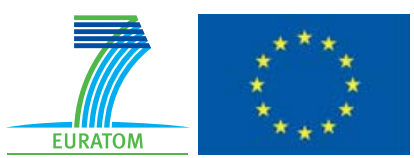

The publication of this research has been funded by the European Union's European Atomic Energy Community's (Euratom) Seventh Framework programme FP7 (2007-2013) under grant agreements $n^{\circ} 249396$, SecIGD, and $n^{\circ} 323260$, SeclGD2. 
TABLE 1. Current member institutions of ENTRAP.

\begin{tabular}{lll}
\hline No. & Institution/Country & Main web page \\
\hline 1 & Nuclear Engineering Seibersdorf GmbH, NES (Austria) & www.nes.at \\
2 & Nuclear Research Centre, SCK•CEN Mol (Belgium) & www.sckcen.be \\
3 & NRI Rez, Nuclear Research Institute Rez, plc. Division of Nuclear & http://www.ujv.cz/en/ \\
& Fuel Cycle Chemestry 250 68 Rez, Czech Republic & \\
4 & Joint Research Centre, JRC, Ispra (European Commission) & https://ec.europa.eu/jrc/en/about/jrc-site/ \\
& ispra \\
5 & VTT Chemical Technology, Espoo (Finland) & www.vtt.fi \\
6 & Commissariat a I'Energie Atomique, CEA Cadarache (France) & www-cadarache.cea.fr \\
7 & Bundesamt f Strahlenschutz, BfS (Germany) & www.bfs.de \\
8 & Forschungszentrum Jülich, FZJ (Germany) & www.fz-juelich.de/iek/iek-6 \\
9 & TU München, ZTWB Radiochemie München RCM (Germany) & www.rcm.tum.de \\
10 & ENEA FSN FISS, Casaccia (Italy) & http://www.enea.it/it/Ricerca_sviluppo/ \\
& nucleare/fissione-nucleare \\
11 & NRG Arnhem, NL (Netherlands) & www.nrg-nl.com \\
12 & Inst. f. Chemistry \& Nuclear Technology, ICNT Warsaw (Poland, new & www.ichtj.waw.pl \\
& member) & \\
13 & ENRESA, Madrid (Spain) & www.enresa.es \\
14 & CIEMAT, Madrid (Spain) & www.ciemat.es \\
& &
\end{tabular}

operators within an effective regulatory regime implemented by national authorities.

In 1989 an ad hoc group of European experts convened under the EC Plan of Action for Radioactive Waste to advise on how to define and implement this final quality control. More precisely, the objective was to "examine the needs, incentives, scopes and ways of implementation of a European network of national QA/QC facilities for radioactive waste products". The conclusion was that national regulators, licensing authorities and laboratories performing quality checks would benefit from European collaboration. In October 1992, following an initiative by the EC, the 'European Network of Testing facilities for the quality checking of Radioactive Waste Packages' (ENTRAP) was founded to promote European collaboration in this field.

Since ENTRAP began, the International Atomic Energy Authority (IAEA) has specified the key elements for the management of radioactive waste in the IAEA membership countries in its publication Safety Standard III-s-1: Establishing a National System for Radioactive Waste Management. Included in this standard is general guidance about the responsibilities of IAEA Member States. The IAEA also provides guidance on the subject of quality assurance for radioactive waste packages. General guidance is provided in the 'Technical Reports Series' No 376: Quality
Assurance for Radioactive Waste Packages (IAEA, 1995). More detailed information is provided in IAEA-TECDOC-680: Quality Assurance Requirements and Methods for High Level Waste Package Acceptability (IAEA, 1992) and IAEATECDOC-864: Requirements and Methods for Low and Intermediate Level Waste Package Accountability (IAEA, 1996). The latter document includes guidance on methods to demonstrate compliance with waste-acceptance criteria and independent verification. Further information is given in other IAEA Technical Reports (IAEA, 1997, 2007).

This short paper describes the objectives, organization and achievements of ENTRAP and lists potential future interactions with other European waste-management forums.

\section{Organisation, objectives and attributes of ENTRAP}

ENTRAP was formally established under the terms of a cooperation agreement between the ENTRAP members. It is a non-profit, financially independent organization (Van Iseghem et al., 1997; Newstead, 1999). Each member pays an annual fee (currently $€ 1000)$ to cover administrative costs, publication of reports, etc. Current ENTRAP members are listed in Table 1. 
Other laboratories, e.g. operated by waste producers or research bodies or in non-EU Member States, carrying out waste-quality checking are also eligible to apply as Associate Members.

Decisions on policy issues, the program of activities, publications and applications for membership are made by a Steering Committee (SC) composed of delegated representatives of the full member organizations of the ENTRAP network. Representatives of EC Member State national regulatory authorities are also invited to attend SC meetings, which are held on an annual basis. The Chairman and a vice Chairman of the SC are elected on a bi-annual basis from amongst its members. Initially the EC provided the secretariat to the network; this is no longer the case, however.

The technical work of the network is undertaken by Working Groups (WGs), each operating under a convener appointed by the SC. There are currently four WGs: WG A - non-destructive methods; WG B - destructive methods; WG C - QA and QC procedures; and WG D - intermediate- and highlevel waste (ILW/HLW). Membership of WGs consists of representatives from both full and associate member organizations. The associate member organisations usually represent the regulators which send observers to the Steering Committee but which have no voting rights. Their support and cooperation in the working groups is welcome, appreciated and unrestricted, however. ENTRAP has performed a number of joint activities related to the verification of conformity of conditioned radioactive waste with regulatory specifications and criteria. Its objectives are to promote and facilitate collaboration in the development, application and standardization of quality checking for waste packages. ENTRAP is therefore engaged in: identification of research and development $(R \& D)$ requirements; joint evaluation of test methods and proficiency testing; co-ordination of national and international standardization of test methods; exchange of information, results and experience; promotion of cooperation, training and young scientist interchange (bi- and multilateral); and promotion of the availability of testing and analytical services. The main strengths of ENTRAP are as follows: its members are laboratories of excellence in the European Union (EU); different analyses and scaling factors (detection limits, uncertainties) are employed; different modelling techniques are employed; and different characterization methodologies (waste types, forms, packages) are used. An overview of the fields of impact of the ENTRAP network is shown in Fig. 1.

\section{Achievements of ENTRAP}

ENTRAP has been involved in: a discussion forum, including technical visits; various $R \& D$ proposals which have been developed, and which have resulted in EU-funded projects; many bi- or multilateral co-operations; many radioactive-waste management schemes which have commenced for mutual benefit; large-volume controls (significant topics for destructive assay (DA) and non-destructive assay (NDA)); and significant scientific output (http://www.en-trap.eu/Reports.html, 2014).

ENTRAP has established valuable links with standards organizations, such as the International Organization for Standardization (ISO) and the American Society for Testing and Materials

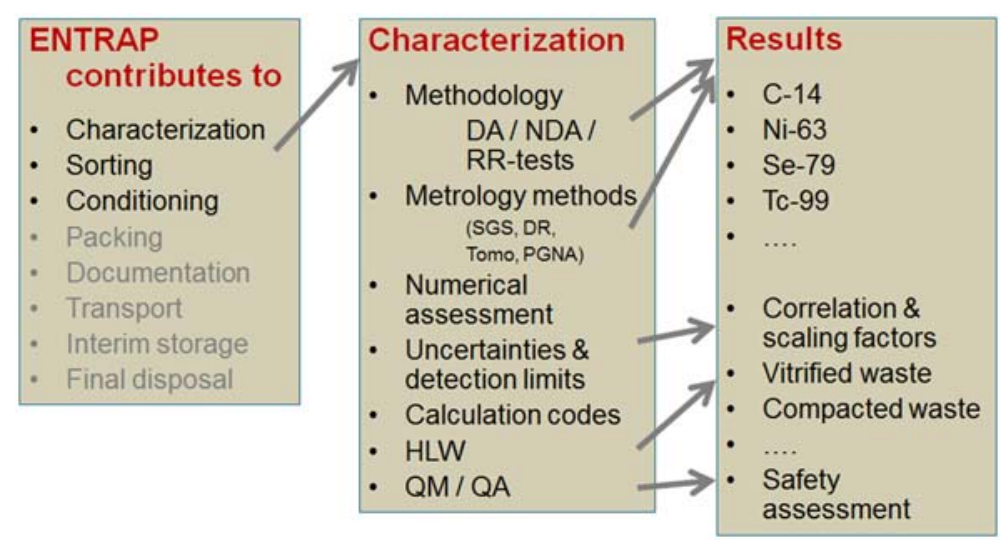

FIG. 1. Impact of the ENTRAP network members' activities. 
TABLE 2. R\&D initiated by ENTRAP and EC-sponsored achievements for: (a) non-destructive assay; and (b) destructive assay.

(a) Non-destructive assay

Improvement of passive and active neutron assay techniques for the characterization of radioactive waste packages (EUR 19121)

Optimization of gamma assay techniques for the standard quality checking of radioactive waste packages and samples (EUR 19127)

Round robin test for non-destructive assays of 220 litres of radioactive waste packages (EUR 19779)

Quality control of nuclear waste packages with a Compton suppression and Ge-telescope detection system

Project on NDA of Large Waste Containers (b) Destructive assay

Evaluation and standardization of fast analytical techniques for destructive radwaste control. 1994-1998.

Qualification of Radiochemical Routines for the Decontamination of Alpha-emitting Nuclides in Conditioned Radioactive Waste. 1994-1998 (EUR 9111).

Development and automation of chemical analytical procedures for determination of non-gamma emitting radionuclides in radioactive waste (DACAPO). 19982002.

nter-laboratory radiochemical analysis comparison on a primary waste flux (INTERLAB). 1998-2002 (EUR 20616).
(ASTM), both of which are active in the development of standards relevant to the quality checking of radioactive waste packages and with laboratories in eastern European countries.

Moreover, ENTRAP has produced recognizable output for quality management/quality assurance
(QM/QA), e.g. for the implementation of regulatory checking or the harmonization of procedures for LLW and ILW (Van Velzen et al., 2000). A discussion of the promotion of quality standards has led to the accreditation and quality certification of a number of ENTRAP member laboratories.

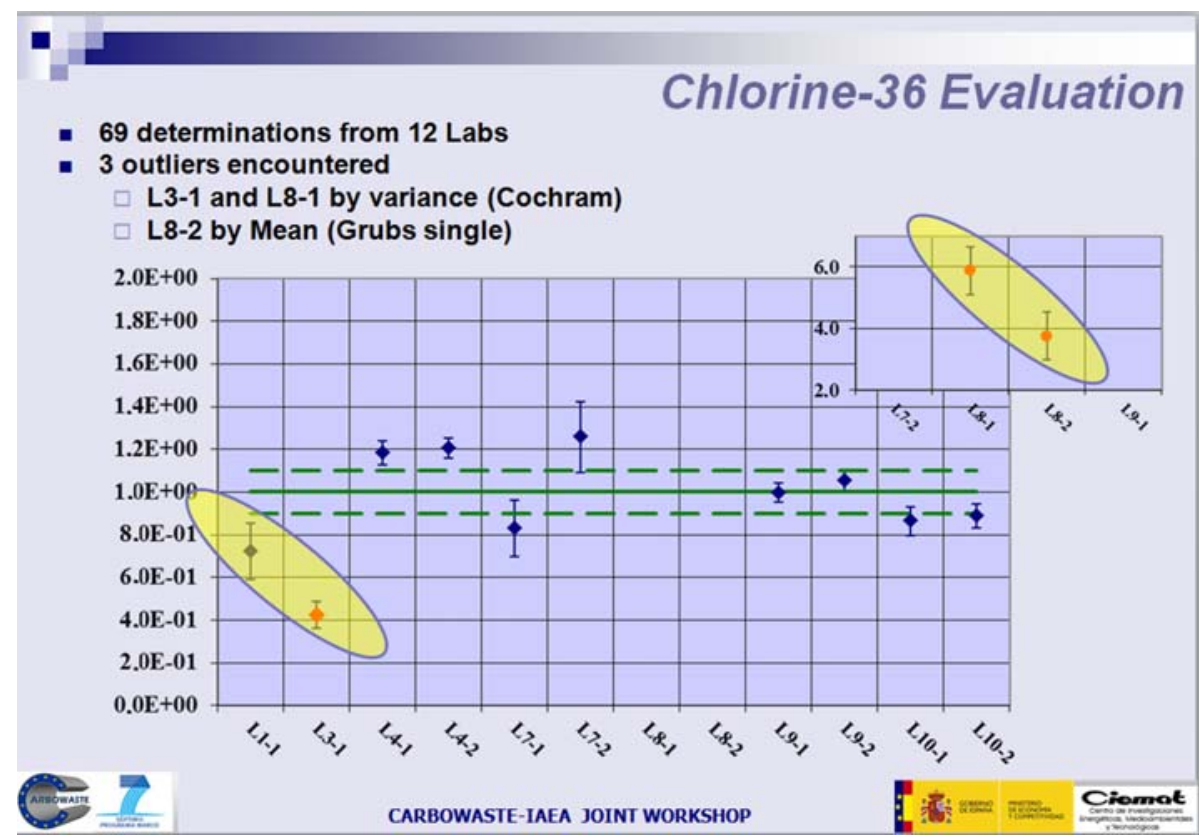

FIG. 2. Round Robin Test (RRT) results of the analytical assessment of Cl-36 for twelve participating laboratories (Piña et al., 2013) 
Particular emphasis has been given to destructive and non-destructive assay of radioactive waste compounds and the assessment of the methodology and harmonization of the experimental metrology and uncertainties (see Table 2).

Significant discussions of large-volume control have included the Characterization Methodology for Complex Geometry at ENRESA (ENRESA, 2013) and implementation of the experimental CINPHONIE platform for large-volume nuclearwaste characterization at Cadarache (Estre and Pettier, 2013).

The methodological standardization of analytical techniques has reached a state-of-the-art level which will be maintained. Thus, round robin tests (RRTs) have been performed on radioactive ionexchange resin samples; the results are currently compiled and will be published shortly. An example of the involvement of ENTRAP member laboratories has been the RRTs on the destructive analysis of irradiated graphite within the Carbowaste EU-project (www.carbowaste.eu) which has resulted in the creation of a 'cookbook' for the analysis of volatile but safety-relevant nuclei, e.g. Cl-36. The RTT results for $\mathrm{Cl}-36$ are shown in Fig. 2

Future ENTRAP projects will consider: free release, (T)NORM, ILW/HLW; harmonization of tests and characterization (ENTRAP has a liaison 'A' membership with ISO); identification of specific legacy and problem waste issues; liaison with other networks within the EU (IGD-TP, NUGENIA, SNETP, etc); training and youngscientist exchange among ENTRAP members.

The young-scientist exchange and training program is a recent activity of ENTRAP and targets the development of knowledge and talents in the ENTRAP member laboratories.

\section{Conclusions}

This paper gives a brief outline of ENTRAP activities and achievements to date. ENTRAP consists of a functional network of cooperating laboratories of excellence within the EU and regards it activities as complementary to those of radioactive-waste disposal (i.e. IGD-TP) and wasteproduction facilities and the networks (i.e. SNETP). ENTRAP recognizes that the topic of disposal of spent nuclear fuel needs to be addressed jointly and like the NUGENIA network, ENTRAP can provide links between the fields of nuclear- waste characterization and radioactive-waste management, experimental assessment facilities, as well as quality-control techniques and standards.

ENTRAP is currently an independent organization and its members (through the SC) wish to continue the network in its current form. It does, however, wish to strengthen its cooperation and liaison with other European networks such as SNETP, IGD-TP and others. Possible areas of future collaboration include: elaboration of methodologies to verify waste-acceptance criteria for different kinds of radioactive-waste packages, e.g. LLW, MLW, HLW; assessment and verification of spent-fuel inventories and their characteristic properties for direct disposal of spent-fuel assemblies; and provision of concise data for waste types, waste properties and inventories for repositorydesign optimization.

\section{References}

Estre, N. and Pettier, J-L. (2013) L'imagerie HauteÉnergie pour le CND: Plateforme CINPHONIE. http:// www.cad.cea.fr/valorisation/pdf/brevets/06-FM-f- $\%$ 20Imagerie $\% 20$ haute $\% 20$ enargie-CND-1010.pdf

ENRESA (2013) Metodología de caracterización de grandes piezas. 031-IF-IN-0345.

IAEA (1992) Quality Assurance Requirements and Methods for high Level Waste Package Acceptability. TECDOC-680, IAEA, Vienna.

IAEA (1995) Quality Assurance for Radioactive Waste Packages. Technical Report Series No. 376, IAEA, Vienna.

IAEA (1996) Requirements and Methods for Low and Intermediate Level Waste Package Acceptability. TECDOC-864, IAEA, Vienna.

IAEA (1997) Characterization of Radioactive Waste Forms and Packages. Technical Report Series No. 383, IAEA, Vienna.

IAEA (2007) Strategy and Methodology for Radioactive Waste Characterization. TECDOC-1537, IAEA, Vienna.

Newstead, S. (1999) The European Network of Testing Facilities for the Quality Checking of Radioactive Waste Packages. TOPSEAL '99 - Commitment to the future environment (Antwerp, Belgium, 10-14 October 1999). Belgian Nuclear Society, ISBN 39520691-4-0. Vol I, pp. 133-137.

Piña, G., Rodriguez, M., Vulpius, D., Comte, J., Brennetot R., Dodaro, A., Duskeas, G., Brune, C., VisserTynova, E., Van Hecke, K., Landesman, C. and Jones, A. (2013) Topical Report on Characterization Methods (part of the EC CARBOWASTE project). 
H. TIETZE-JAENSCH ETAL.

Van Iseghem, P., Brunel, G., Lierse, C., Morales, A., Odoj, R., Troiani, F. and Hugon, M. (1997) The European Network for Quality Checking of Waste Packages: objectives and status. Management and Disposal of Radioactive Waste (T. McMenamin, editor). EUR 17543, pp. 286-295.
Van Velzen, L., Tamboer, L., Dionisi, M., Delepine, J., Morales, A., Steinmetz, H., Borgermans, P., Neubauer, J. and Daish, S. (2000) Quality assurance and quality control of low and medium-level radioactive waste packages. EUR 19615. 